\title{
Economic Effects of Precipitation Enhancement in the Corn Belt
}

\author{
Philip Garcia, * Stanley Changnon and Musa Pinar \\ Climate and Meteorology Section, Illinois State Water Survey, Champaign, Illinois
}

(Manuscript received 23 July 1988, in final form 20 July 1989)

\begin{abstract}
Policy formulation in weather modification requires an understanding of the economic effects from altered weather. The focus of this study is to provide insight into the beneficiaries of a functioning weather modification technology when applied at various spatial and temporal levels. An econometric model which links the corn/ soybean production to U.S. cattle, hog and poultry sectors is used to determine the effects of precipitation enhancement in the U.S. Corn Belt, a humid climatic region. A regional supply formulation permits assessment of weather modification on production, prices, revenues to producers, and savings in consumers expenditures on meat. The results provide insight into the distribution of economic effects, emphasize the importance of careful planning in the use of weather modification technology, and provide useful information on the roles of local, state, and federal governments in the support of weather modification.
\end{abstract}

\section{Introduction}

Since 1950 the development of weather modification capabilities in the United States has been largely a federal activity. A major assessment of the field in 1977 78 recommended an expanded federal effort (Weather Modification Advisory Board 1978) which has never materialized. In subsequent years there has been a policy debate over whether the development of weather modification capabilities should be the function of the states or the federal government (Changnon and Lambright 1987). Specifically, questions have been asked regarding who should support the research and development ( R \& D) of weather modification, the federal and/or state levels; and in turn, who should pay for the conduction of operational weather modification projects, those benefitting in the immediate area, the states or the federal government (Changnon 1980). The Congress currently has a policy of federal and state responsibility towards $\mathrm{R} \& \mathrm{D}$ of precipitation modification. As a result of these debates and the interests of Congress, a federal-state mix of support currently exists for precipitation modification research.

There are several factors affecting the policy debate (federal vs. state responsibility) over R \& D for weather

\footnotetext{
* Also affiliated with the Department of Agricultural Economics, University of Illinois at Urbana-Champaign.
}

Corresponding author address: Dr. Philip Garcia, Dept. of Agricultural Economics, University of Hlinois at Urbana-Champaign, 305 Mumford Hall, 1301 West Gregory Drive, Urbana, IL 61801. modification, but the two principal ones are the uncertainties over the economic impacts of a modification technology and the level of modification capability (Changnon 1980b). The potential magnitude of the benefits (Sonka 1979), and who might benefit and lose, are included among the economic impact issues surrounding the utilization of weather modification (Changnon 1980c). Most earlier efforts to assess the economic impact of precipitation modification focused on point expressions ( $X$ inches of added rain equals $Y$ crop yield increase) as a basis of defining benefits. A technology assessment of hail suppression did investigate the regional and national impacts of different levels of suppression capabilities and identified the beneficiaries as well as the costs of developing the capabilities (Changnon et al. 1978).

Also, debates have been held within local areas and states about who should pay for weather modification operations. In general, local citizens interested in the use and benefits of the technology have supported the costs, although on a voluntary basis, leading to unhappiness over the nonpaying locals. This has led to local tax-supported procedures and development of weather modification districts. In some states such as Utah and North Dakota, a mix of local, county and state funding for operational cloud seeding programs has developed (Changnon 1983).

Relevant to these policy debates about who should be responsible for the $\mathrm{R} \& \mathrm{D}$ and for the operational costs is a clear understanding of the economic impacts from altered weather. The central objective of this study is to provide insight into the beneficiaries of a functioning precipitation modification technology when 
applied at various spatial and temporal levels. ${ }^{1}$ An econometric model has been developed that permits determination of the effects of a simulated precipitation modification in a key agricultural area of the United States-the Corn Belt, a humid climatic region. A regional supply response formulation based on Crop Reporting Districts (CRDs) permits an assessment of the effects of changing weather in specific regions on production, prices, change in revenues to producers, and savings to consumers on meat products. The effects of simulated rainfall changes at the time of the growing season, known to be most relevant to corn and soybean production (July and August) over various sized areas, are examined. The simulations are performed for the 10-year period of 1983-92 and are useful because they permit the isolation of the effects of the precipitation modification.

The results provide insight into the distribution of the revenues to various geographic regions and emphasize the importance of careful planning in the development and use of a precipitation modification technology. They further provide information useful in developing policy about the roles of the local, state, and federal governments in the support of weather modification.

The paper is organized as follows. First, a description of the model, concentrating on an overview of its salient features and crop response relationships, is presented. The next sections provide information concerning the model's validation and the simulated precipitation modification. The validation section discusses selected results of the model concentrating on the important yield and acreage relationships. The final sections present the results of the simulation with a summary and conclusions of the analysis.

\section{The model}

An economic model of supply and demand is used to describe the structure of the corn and soybean markets and their relationship to the U.S. livestock sector. The model is dynamic, nonlinear (in variables) and contains 520 equations of which 228 are behavioral equations and 292 are identities. It is estimated over the period 1961-82 and is annual in nature. The basic structure of the livestock and feed sector is presented in Offutt and Blandford (1984), which explains livestock production, consumption and their linkages to the feed sector. The present model extends their effort primarily by spatially disaggregating corn and soybean output relationships to measure the effects of weather

\footnotetext{
${ }^{1}$ The analysis focuses on the direct effects of changing precipitation on corn and soybean production and prices and their influence on livestock production and prices. Other indirect effects (e.g., changing income and employment) may also be important but are not considered here.
}

on production. ${ }^{2}$ Weather directly influences the production and prices of corn and soybeans through its effect on annual yields. To quantify this effect, monthly temperature and precipitation are included in estimated yield relationships for various spatial aggregates. This specification, along with regional specific acreage response equations, permits the measurement of the effects of regional changes in precipitation.

Here, the presentation of the model is divided into two components: 1) an overview and 2) a discussion of the regional output response models. The overview provides a general description of the model and briefly traces the effects of increasing precipitation. The regional output response section identifies the variables used to measure the changes in output concentrating on the effects of weather on crop yields. The format of the presentation permits a focus consistent with the objectives of the paper and emphasizes the unique aspects of the model. For the interested reader, the Appendix provides a more detailed discussion of the model and procedures.

\section{a. An overview}

The economic model explains the production of corn, soybeans, and livestock, as well as the consumption of U.S. corn and soybean domestically and in the export market. Figure 1 provides a stylized representation of the model's components. The demand for livestock products is modeled at the wholesale level where because supply is largely fixed in the short run, prices adjust to clear the market. Hog, beef and poultry production are specified to reflect biological lags in output and are a function of relative prices (lagged) of livestock and corn and soybean meal at the time the production decision is made. The feed demand for corn and soybean meal are derived from current livestock production levels. The demand for export food and seed and industrial use and stocks represents the other components of the demand for corn and soybeans. The production of corn and soybeans is the summation of the products of their respective acreage and yields. The acreage is influenced by their relative prices (lagged), government programs and previous acreage decisions. Yields are specified as a function of weather variables and changing technology. The current prices of corn and soybeans are determined by the interaction of current production and the demands for these commodities.

\footnotetext{
${ }^{2}$ Commonly, econometric models that include a crop sector specify national yield and acreage response using two equations for each crop and national level data. Here, the terminology referring to spatial disaggregation or various spatial aggregates indicates that the supply response for corn and soybeans is modeled on a more regional basis using various geographic areas as the units of measurement. In each area, specific yield and acreage functions based on more regional data are estimated and used in the analysis. National production is the sum of the output in the different areas. See the regional crop response section below for a complete specification of these units.
} 


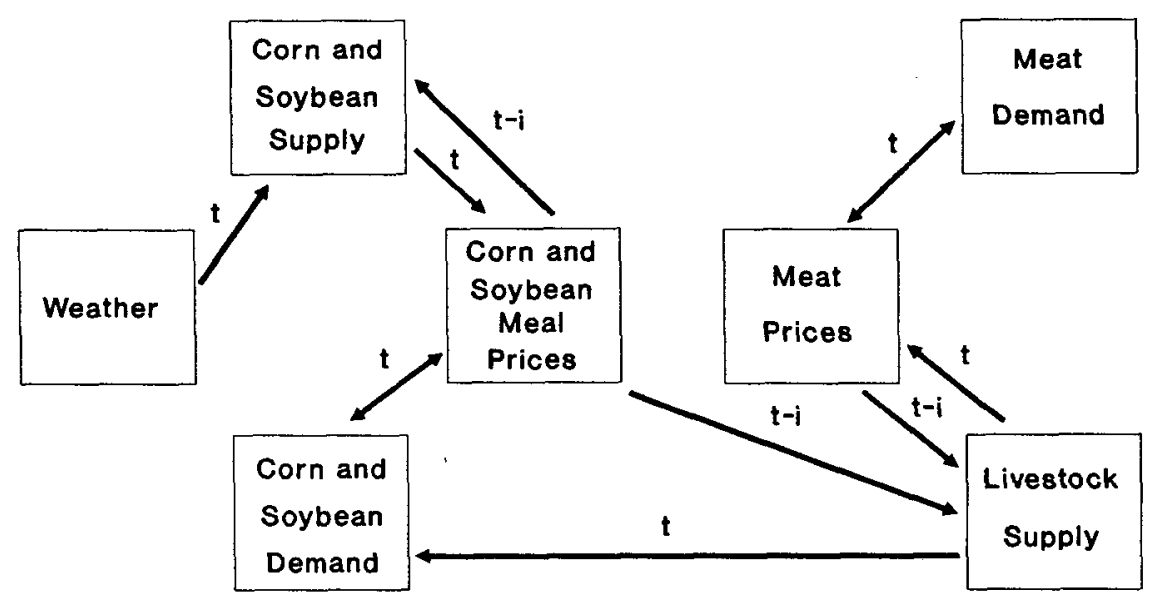

$t$ represents years and $t-1$ lagged effects.

FIG, 1. Stylized flowchart of the model.

Price and quantity are the important links between the components of the model. Lagged relative prices of livestock and feed affect subsequent production of livestock. This production directly influences the quantity of corn and soybeans consumed. It also interacts with demand to generate prices for meat products which affect consumer expenditures on meat and the subsequent attractiveness of livestock production. Changes in the quantity of corn and soybean have repercussions in the model through their influence on prices. For example, increasing the supply of grain through augmenting precipitation has an immediate effect of increasing the amount of available grain for use, which reduces its price. The lower price of grain makes future livestock production more attractive, increasing subsequent livestock output. In turn, the increased livestock production reduces meat prices that consumers face.

\section{b. Regional crop response}

The largest component of the model involves the specification of corn and soybean production (194 of the 228 estimated equations). The total production of corn and soybeans in any period is the summation of the product of yield and acreage. Average yields are influenced by the weather as measured by precipitation and temperature and changing technology. Acreage response is modeled in a partial adjustment framework which includes lagged relative corn and soybean prices, lagged acreage, and government programs (diversion programs, effective loan rates and support programs; Houck and Ryan 1972). In several of the corn and soybean acreage functions, early growing season precipitation is also included to examine its effect on shifting from corn to soybeans.

To capture the effect of weather on production, the yield and acreage response functions are specified at various levels of spatial aggregation. Crop Reporting District (CRD) data is used for the five largest Midwest corn and soybean producing states (Illinois, Iowa, Ohio, Indiana and Missouri). ${ }^{3}$ For corn, state level yield and acreage response functions are specified for Nebraska, Minnesota and Wisconsin. For soybeans, state level functions are estimated for the two next largest producing states in the region, Minnesota and Wisconsin. To complete the crop supply component of the model, yield and acreage functions are specified for each crop for the remainder of the states combined.

The results of the estimated equations are too numerous to discuss here. Instead, first we provide a brief overview of the findings regarding the acreage response functions. Then, we discuss more thoroughly the yield response functions for a specific state, Illinois, which characterizes many of the relationships encountered in the yield modeling. A more complete validation of the production response relationships is presented in the following section.

The results of the estimated acreage response functions varied somewhat across similar spatial units (e.g., CRDs) and levels of spatial aggregation (i.e., CRDs compared to state). The adjusted coefficients of determination which measure the degree of explanatory power in the estimated relationships ranged from 0.65 to 0.85 . Lower coefficients of determination were usually associated with smaller units of spatial aggregation and with land that is often considered more economically marginal in the production of corn and soybeans. Lagged own acreage and own price were positively related to acreage response. The price elasticities of supply, which measure the percent change in acreage re-

\footnotetext{
${ }^{3}$ Each state is divided into nine CRDs which are rather homogenous in production technology. Working with yield functions, Offutt (1988) has shown that functions estimated at the CRD level as opposed to the county level suffer from limited aggregation bias.
} 
TABLE 1. Illinois crop reporting district corn yield relationships.

\begin{tabular}{|c|c|c|c|c|c|c|c|c|c|c|}
\hline \multirow{2}{*}{$\begin{array}{l}\text { Crop reporting } \\
\text { districts }\end{array}$} & \multicolumn{10}{|c|}{ Independent variables ${ }^{a}$} \\
\hline & Time & MYP & PRSP & JP & JLP & AUP & JLT & AUT & DW & $\bar{R}^{2}$ \\
\hline Northwest 1 & $\begin{array}{c}2.20 \\
(0.19)\end{array}$ & $\begin{array}{c}-3.02 \\
(0.66)\end{array}$ & & & $\begin{array}{c}1.30 \\
(0.82)\end{array}$ & & $\begin{array}{c}-1.83 \\
(0.84)\end{array}$ & & 2.45 & 0.88 \\
\hline Northeast 2 & $\begin{array}{c}2.76 \\
(0.25)\end{array}$ & $\begin{array}{c}-3.85 \\
(0.30)\end{array}$ & & $\begin{array}{l}-1.27 \\
(1.04)\end{array}$ & $\begin{array}{c}1.87 \\
(1.27)\end{array}$ & & $\begin{array}{c}-1.56 \\
(1.08)\end{array}$ & & 2.90 & 0.86 \\
\hline West 3 & $\begin{array}{c}2.55 \\
(0.23)\end{array}$ & $\begin{array}{c}-1.95 \\
(0.88)\end{array}$ & & & $\begin{array}{c}0.78 \\
(0.77)\end{array}$ & $\begin{array}{l}-2.40 \\
(0.68)\end{array}$ & $\begin{array}{l}-2.75 \\
(0.77)\end{array}$ & & 1.69 & 0.87 \\
\hline Central 4 & $\begin{array}{c}2.21 \\
(0.32)\end{array}$ & $\begin{array}{l}-2.62 \\
(1.17)\end{array}$ & & & $\begin{array}{c}3.37 \\
(1.81)\end{array}$ & & $\begin{array}{c}-3.33 \\
(1.32)\end{array}$ & $\begin{array}{c}-1.39 \\
(1.48)\end{array}$ & 1.64 & 0.79 \\
\hline East 5 & $\begin{array}{c}2.04 \\
(0.28)\end{array}$ & $\begin{array}{l}-2.09 \\
(1.13)\end{array}$ & $\begin{array}{c}1.22 \\
(0.52)\end{array}$ & & $\begin{array}{c}1.97 \\
(1.27)\end{array}$ & & $\begin{array}{l}-4.36 \\
(1.30)\end{array}$ & $\begin{array}{c}-2.21 \\
(1.05)\end{array}$ & 2.33 & 0.81 \\
\hline West-southwest 6 & $\begin{array}{c}2.37 \\
(0.27)\end{array}$ & $\begin{array}{l}-2.67 \\
(1.06)\end{array}$ & & & $\begin{array}{c}2.89 \\
(0.85)\end{array}$ & $\begin{array}{c}1.74 \\
(1.30)\end{array}$ & $\begin{array}{c}-2.95 \\
(0.97)\end{array}$ & $\begin{array}{c}-1.64 \\
(1.03)\end{array}$ & 1.97 & 0.83 \\
\hline East-southeast 7 & $\begin{array}{c}1.83 \\
(0.30)\end{array}$ & $\begin{array}{c}-0.89 \\
(0.83)\end{array}$ & $\begin{array}{c}0.45 \\
(0.36)\end{array}$ & & $\begin{array}{c}3.80 \\
(1.14)\end{array}$ & $\begin{array}{l}2.20 \\
(1.28)\end{array}$ & $\begin{array}{c}-2.51 \\
(1.12)\end{array}$ & $\begin{array}{l}-2.79 \\
(1.03)\end{array}$ & 2.07 & 0.84 \\
\hline Southwest 8 & $\begin{array}{c}1.57 \\
(0.41)\end{array}$ & & & & $\begin{array}{c}4.37 \\
(1.57)\end{array}$ & $\begin{array}{c}3.88 \\
(1.92)\end{array}$ & $\begin{array}{c}-1.48 \\
(1.43)\end{array}$ & $\begin{array}{l}-2.60 \\
(1.38)\end{array}$ & 1.50 & 0.69 \\
\hline Southeast 9 & $\begin{array}{c}1.73 \\
(0.34)\end{array}$ & & $\begin{array}{c}0.44 \\
(0.35)\end{array}$ & $\begin{array}{l}-2.48 \\
(1.35)\end{array}$ & $\begin{array}{c}3.72 \\
(1.53)\end{array}$ & & $\begin{array}{c}-1.49 \\
(1.00)\end{array}$ & $\begin{array}{l}-2.55 \\
(1.20)\end{array}$ & 1.93 & 0.70 \\
\hline
\end{tabular}

a Variable definitions: time (linear trend); MYP, PRSP, JP, JLP, and AUP (May, preseason, June, July and August precipitation, respectively, in inches); JLT and AUT (average July and August temperature, respectively, in degrees Fahrenheit). Figures in parentheses are standard errors. DW is the Durbin Watson statistic, $\bar{R}^{2}$ is the adjusted coefficient of determination (the average $\bar{R}^{2}$ for the CRDs during the period is 0.81 ).

sponse for a one percent change in price, were reasonable and ranged from 0.56 to 0.4 . The effect of government programs was the most difficult factor to quantify having minimal effect on acreage response in some areas, while in other areas its influence was significant in acreage decisions. The influence of early growing season precipitation on acreage response was not very dramatic but when significant indicated, as expected, that an increase in precipitation resulted in a shifting of acreage to the crop with the shorter growing season (i.e., from corn to soybeans).

The specification of the yield functions also was performed at various levels of spatial aggregation. At each level, the yield relations were specified as linear functions of a time trend (a technology proxy) and weather variables [preseason and monthly precipitation through the growing season (May, June, July and August) and monthly temperature for July and August ]. To test for the possibility of a yield plateau, quadratic trend terms were also included. Selection for inclusion from among the set of possible monthly temperature and precipitation variables was based on a variable's coefficient being larger than its standard error. ${ }^{4}$

The results of the corn and soybean yield functions for Illinois at the CRD level are presented in Tables 1 and 2. All equations are estimated using ordinary least squares (OLS). OLS is inappropriate if there is a nonconstant residual variance. With the weather variables included, no evidence of nonconstant residual vari-

\footnotetext{
${ }^{4}$ See Garcia et al. (1987) for a discussion of the factors influencing yields.
}

ances existed. The adjusted coefficients of determination for the estimated relationships range from 0.69 to 0.88 , which is reasonable given the variable behavior of spatially disaggregated corn and soybean yields.

The findings shed some light on the relationship between yields, technology and the sensitivity of changes in crop production associated with changing weather. In all the CRDs for both crops, technology as measured by the linear trend is an important factor in influencing yields. For these CRDs, the trend term enters only linearly providing no support for a yield plateau. The magnitudes of the trend coefficients, which reflect the yearly change in the bushels/acre yield due to technology, are considerably larger in corn than soybeans reflecting the successful development of corn highyielding varieties.

Several similarities and differences emerge in examining the effects of the weather variables on crop yields across the CRDs. First, pre- and early growing season precipitation has a somewhat limited effect on crop yields. Preseason precipitation has a small but positive effect on crop yields, while precipitation during the early stages of the growing season adversely affects output. Second, the primary variables influencing crop yields are July and August precipitation and temperatures. Third, corn yields are more sensitive to changes in growing season precipitation than soybean yields. For example, an increase in July precipitation of one inch in the Central CRD results in an increase of 3.37 bushels/acre of corn and only a 0.985 bushels /acre increase in soybeans. Finally, increases in growing season precipitation have largest effects on bushels/acre yields in the southern, drier portions of the state. 
TABLE 2. Illinois crop reporting district soybean yield relationships.

\begin{tabular}{|c|c|c|c|c|c|c|c|c|c|c|}
\hline \multirow{2}{*}{$\begin{array}{l}\text { Crop reporting } \\
\text { districts }\end{array}$} & \multicolumn{10}{|c|}{ Independent variables ${ }^{a}$} \\
\hline & Time & MYP & PRSP & JP & JLP & AUP & JLT & AUT & DW & $\bar{R}^{2}$ \\
\hline Northwest 1 & $\begin{array}{c}0.47 \\
(0.04)\end{array}$ & $\begin{array}{c}-0.64 \\
(0.22)\end{array}$ & & & $\begin{array}{c}0.66 \\
(0.24)\end{array}$ & $\begin{array}{c}0.59 \\
(0.16)\end{array}$ & & & 2.65 & 0.85 \\
\hline Northeast 2 & $\begin{array}{c}0.36 \\
(0.05)\end{array}$ & $\begin{array}{c}-0.57 \\
(0.37)\end{array}$ & & & $\begin{array}{c}0.39 \\
(0.35)\end{array}$ & $\begin{array}{c}0.63 \\
(0.23)\end{array}$ & & & 2.35 & 0.73 \\
\hline West 3 & $\begin{array}{c}0.45 \\
(0.04)\end{array}$ & $\begin{array}{c}-0.86 \\
(0.26)\end{array}$ & & & $\begin{array}{c}0.30 \\
(0.19)\end{array}$ & & & & 2.10 & 0.78 \\
\hline Central 4 & $\begin{array}{c}0.42 \\
(0.05)\end{array}$ & $\begin{array}{c}-3.70 \\
(3.39)\end{array}$ & $\begin{array}{c}0.11 \\
(0.10)\end{array}$ & $\begin{array}{c}-0.36 \\
(0.25)\end{array}$ & $\begin{array}{c}0.99 \\
(0.32)\end{array}$ & $\begin{array}{c}0.48 \\
(0.27)\end{array}$ & & & 1.80 & 0.76 \\
\hline East 5 & $\begin{array}{c}0.39 \\
(0.05)\end{array}$ & $\begin{array}{c}-3.08 \\
(2.83)\end{array}$ & & $\begin{array}{c}-0.28 \\
(0.21)\end{array}$ & $\begin{array}{c}0.50 \\
(0.25)\end{array}$ & $\begin{array}{c}0.59 \\
(0.23)\end{array}$ & $\begin{array}{c}-0.35 \\
(0.24)\end{array}$ & & 1.84 & 0.79 \\
\hline West-southwest 6 & $\begin{array}{c}0.44 \\
(0.24)\end{array}$ & $\begin{array}{c}-0.42 \\
(0.12)\end{array}$ & & & $\begin{array}{c}0.62 \\
(0.22)\end{array}$ & & & . & 2.10 & 0.82 \\
\hline East-southeast 7 & $\begin{array}{c}0.42 \\
(0.05)\end{array}$ & & & & $\begin{array}{c}0.73 \\
(0.26)\end{array}$ & $\begin{array}{c}0.69 \\
(0.32)\end{array}$ & $\begin{array}{c}-0.39 \\
(0.26)\end{array}$ & $\begin{array}{c}-0.28 \\
(0.26)\end{array}$ & 1.67 & 0.82 \\
\hline Southwest 8 & $\begin{array}{c}0.43 \\
(0.05)\end{array}$ & & $\begin{array}{c}0.20 \\
(0.07)\end{array}$ & & $\begin{array}{c}0.83 \\
(0.22)\end{array}$ & $\begin{array}{c}0.41 \\
(0.31)\end{array}$ & $\begin{array}{c}-0.91 \\
(0.21)\end{array}$ & & 2.00 & 0.85 \\
\hline Southeast 9 & $\begin{array}{c}0.33 \\
(0.04)\end{array}$ & & $\begin{array}{c}0.06 \\
(0.05)\end{array}$ & & $\begin{array}{c}1.04 \\
(0.22)\end{array}$ & $\begin{array}{c}0.51 \\
(0.23)\end{array}$ & $\begin{array}{c}-0.69 \\
(0.19)\end{array}$ & & 2.50 & 0.84 \\
\hline
\end{tabular}

a See Table 1 for a definition of the variables. The average $\bar{R}^{2}$ for the CRDs during the period is 0.80 .

The results from Illinois were characteristic of the yield functions in other areas. Yields for corn and soybeans were positively related to the technology variable with a quadratic trend variable only rarely emerging as significant. For corn and soybeans, the most important weather variables were July and August precipitation and temperatures. For both crops, there appeared a tendency for the weather variables to have their more dramatic effects in the southern, drier regions.

\section{Model validation}

Using the mathematics of difference equations, stability conditions for a linear, nonstochastic model can be described. Model stability is important as it is the general perception that real world variables and relationships behave in a fundamentally stable fashion. Consequently, an acceptable empirical model will reflect this characteristic real world behavior. If, however, the structural form of the model's equations is other than nonstochastic and linear, as is the case here, then no analytical solution to stability conditions can be found. Nevertheless, the validity of the model, meaning its ability to reproduce real world events, can be evaluated via simulation, which is basically the numerical solution to the system of equations over time. That is, comparison of the original data series with the simulated series for the endogenous variables can provide a useful device to assess the validity of the model. ${ }^{5}$ This procedure, called expost simulation, is used here.

\footnotetext{
${ }^{5}$ Endogenous refers to variables whose values are determined in the model. Exogenous variables are those whose values are determined outside the model and hence, are given.
}

The historical simulation can be done using the reduced form if the model is linear. The nonlinearities here prevent the use of the reduced form directly. Furthermore, the presence of lagged variables which are determined in the system may also cause difficulties. As a result, the model is simulated in its structural form, using an iterative solution procedure. Initial values for the variables to be determined are provided, and the model solves for subsequent values given the predetermined variable values.

The results of the historical simulation are compared to the original data series using the percent root mean square error (PRMSE). Table 3 provides the findings of the production relationships for corn and soybeans. For purposes of brevity, the PRMSE for the five major corn and soybean producing states in the Midwest reflects averages of the PRMSE for the nine CRDs in each state. The other PRMSEs represent the errors associated with that particular level of spatial aggregation. Table 4 presents the PRMSE for the other components of the model. The validation findings of the Offutt and Blandford version of the model are also presented for comparative purposes.

An examination of the results suggests that the model can be judged to perform in an acceptable manner. For the disaggregated corn and soybean acreage and yield relationships, the PRMSEs were generally low except in the case of Ohio soybean acreage and Missouri corn acreage and yield relationships. As expected, the more aggregate relationships (i.e., state and the remainder of the United States) demonstrated smaller errors, a result of the reduced variability often encountered in using large, averaged aggregates.

For the other components of the model, the PRMSEs varied considerably. For prices, the PRMSEs ranged 
TABLE 3. Validation results of the corn and soybean output response, 1961-82.

\begin{tabular}{lccc}
\hline \multicolumn{1}{c}{ Variable } & PRMSE & Variable \\
\hline $\begin{array}{l}\text { Corn Production } \\
\text { b }\end{array}$ & & Soybean Production & Illinois Acreage \\
Illinois Acreage & 6.17 & Illinois Yields & 8.34 \\
Illinois Yields & 8.65 & Iowa Acreage & 7.76 \\
Iowa Acreage & 4.87 & Iowa Yields & 8.21 \\
Iowa Yields & 10.92 & Indiana Acreage & 6.65 \\
Indiana Acreage & 6.35 & Indiana Yields & 7.42 \\
Indiana Yields & 10.57 & Ohio Acreage & 7.97 \\
Ohio Acreage & 6.61 & Ohio Yields & 9.57 \\
Ohio Yields & 7.28 & Missouri Acreage & 9.24 \\
Missouri Acreage & 15.52 & Missouri Yields & 12.12 \\
Missouri Yields & 17.24 & & 11.98 \\
Nebraska Acreage & 11.20 & & \\
Nebraska Yields & 8.44 & Minnesota Acreage & 12.10 \\
Minnesota Acreage & 7.56 & Minnesota Yields & 11.15 \\
Minnesota Yields & 6.19 & Wisconsin Acreage & 9.23 \\
Wisconsin Acreage & 6.46 & Wisconsin Yields & 8.88 \\
Wisconsin Yields & 4.09 & Remainder of U.S. Acreage & 6.57 \\
Remainder of U.S. Acreage & 5.02 & Remainder of U.S. Yields & 7.12 \\
Remainder of U.S. Yields & 5.23 & & \\
\hline
\end{tabular}

a PRMSE is the percent root mean square error.

b The PRMSE for Illinois, lowa, Indiana, Ohio and Missouri represents an average of the nine crop reporting districts in each state.

from $8 \%$ to $16 \%$, with the corn and soybean farm prices at about $11 \%$. Livestock prices tended to register somewhat higher PRMSEs, except for poultry. For the components of livestock production, the PRMSEs also varied appreciably. However, the PRMSEs for per capita consumption of fed beef, nonfed beef, pork and poultry were rather low-12, 13, 7 and 4 percent, respectively. The largest PRMSEs were encountered in the import, U.S. domestic disappearance and stock relationships. The results of the import component are a reflection

TABLE 4. Validation results for various components of the model, 1961-82.

\begin{tabular}{|c|c|c|c|}
\hline Variable & PRMSE $^{\mathbf{a}}$ & Variable & PRMSE \\
\hline \multicolumn{2}{|l|}{ Prices } & \multicolumn{2}{|l|}{ Hog production } \\
\hline Corn & $11(23)$ & \multicolumn{2}{|l|}{ Dec-May: } \\
\hline Soybeans (farm) & 11 & Sow Farrowings & g) $(8)$ \\
\hline Soybean Meal & 12 & Pig Crop & $9(9)$ \\
\hline Soybean (wholesale) & 11 & Sow Slaughter & $9(8)$ \\
\hline Fed Beef & $11(12)$ & Gilts added & $16(18)$ \\
\hline Nonfed Beef & $16(12)$ & Hog Production & $7(8)$ \\
\hline Feeder Cattle & $15(20)$ & Pork Consumption per capita & $7(8)$ \\
\hline Hog, Dec.-May & $13(19)$ & \multirow{2}{*}{\multicolumn{2}{|c|}{ Jun-Nov }} \\
\hline Hog, June-Nov. & $13(31)$ & & \\
\hline Poultry & $8(10)$ & $\begin{array}{l}\text { Breeding Inventory } \\
\text { Sow Farrowings }\end{array}$ & $\begin{array}{l}9(8) \\
5(7)\end{array}$ \\
\hline Beef production & & Pig Crop & $5(7)$ \\
\hline Beef Cow Inventory & $2(2)$ & Sow Slaughter & $13(14)$ \\
\hline Calf Crop & $2(2)$ & Gilts added & $17(13)$ \\
\hline Heifers added & $7(7)$ & Hog Production & $7(11)$ \\
\hline Feeder Cattle Supply & $8(7)$ & Yearly Pork Consumption per Capita & $7(8)$ \\
\hline Cow Slaughter & $13(14)$ & \\
\hline Feeder Cattle Average Weight & $2(3)$ & Corn Fed to beef & $23(34)$ \\
\hline Fed beef slaughter & $8(15)$ & Corn Fed to Hogs Dec-May & $9(8)$ \\
\hline Fed beef consumption per capita & $12(18)$ & Corn Fed to Hogs Jun-Nov & $8(10)$ \\
\hline Nonfed beef consumption per capita & $13(18)$ & Corn, Food, Seed, Industrial Use & $5(4)$ \\
\hline Poultry production & & Corn Fed to Poultry & $10(8)$ \\
\hline \multirow[t]{2}{*}{ Production } & \multirow[t]{2}{*}{$4(6)$} & Corn Fed to Dairy & $6(7)$ \\
\hline & & Soybean Meal Consumption & 17 \\
\hline World corn imports & & Corn Stocks & $35(29)$ \\
\hline Japan, et al. & $23(18)$ & Soybean Stocks & 40 \\
\hline Eastern Europe, et al. & $22(45)$ & & \\
\hline European community & $30(7)$ & & \\
\hline Canada, et al. & $18(22)$ & & \\
\hline
\end{tabular}

${ }^{\text {a }}$ PRMSE is the percent root mean square error. Numbers in the parenthesis are the PRMSE from Offutt and Blandford (1984). 
of the difficulty of modeling this component of the economy. For the domestic disappearance of corn and soybean meal, the values of the PRMSE were between 22 and 5 percent. Larger deviations were encountered for the domestic stock relationships. Given the difficulties in empirically modeling private and government stock behavior, these results are not too surprising.

A comparison of the results of the model to the Offutt and Blandford (1984) formulation indicates similar validation findings. Direct comparisons of the corn and soybean output response components are not very meaningful because of the more detailed spatial analysis performed in this analysis. ${ }^{6}$ However, for the other components of the model the validation findings are rather consistent. One notable difference emerges; on balance, the model here generates lower errors in prices but somewhat higher errors in the stock variables.

\section{Simulation of precipitation modification}

The model discussed above was used to simulate the economic effects of successful precipitation modification during the corn and soybean growing season. A rain enhancement capability of $20 \%$ on summer rainfall was assumed as an estimate of a possible future technology (Changnon 1986). That is, we assumed a future modification capability in the Midwest could achieve an average increase of $20 \%$ in the July and August total rainfall values. This level is consistent with the METROMEX findings from inadvertent modification of summer rainfall by the city of St. Louis (Changnon et al. 1981). This is not to say that every day of rain would be increased by $20 \%$, a highly unlikely outcome, but rather the "average technological performance" would be to produce an increase of $20 \%$ in summer monthly rainfall. We also assume that a functioning precipitation modification operation can be extended over unlimited areas, given resources are available to operate radars and seeding aircraft systems, and for personnel to perform these operations. ${ }^{7}$

As indicated above, the validated model is used to examine the effect of successful weather modification at various levels of aggregation and spatial units. Based on the starting values of the variables in the model, the

\footnotetext{
${ }^{6}$ The PRMSEs for the aggregate U.S. corn acreage and yield relationships were 5 and 4 percent, respectively (Offutt and Blandford 1984).

${ }^{7}$ Based on past experience, this last assumption is rather reasonable (Changnon et al. 1978). However, as pointed out by an anonymous reviewer, the costs of providing such a modification system are difficult to calculate. One estimate suggests that the costs may be rather area constant, about $25 \$$ per acre (Changnon et al. 1978). This figure does not include current and future expenditures on the development of modification capability and does account for uncertainties associated with possible regional differences and possible liability increases. Because of these uncertainties, the cost figures are not included in subsequent calculations. This does not detract from the focus of the work which highlights the distributional effects of the precipitation modification across regions.
}

model simulates the path of the endogenous variables over time. This generates a base run of the model. Then, the precipitation is changed in various spatial units and the model simulates again to ascertain the impact of modified precipitation. The simulations are performed for a one-year and a five-year increase in precipitation for the period 1983 to 1992 .

The out-of-sample simulation is useful because it permits the isolation of the effect of the precipitation modification. However, it can cause problems because the paths of the exogenous variables must be.extrapolated over the simulation period. These variables deal with forces in the export sector, technical aspects of livestock and grain production, the policy arena, and macroeconomic influences. It is difficult to predict how these variables will change and any interactions that might occur. In light of this, it was decided to follow a general set of rules to determine the values of these exogenous variables. The weather variables are assumed to take the average value of the preceding ten years. All technical production relationships and feeding ratios not influenced by prices are assumed to hold constant at a value of the last three years of the data (1979-82). Price indices and prices exogenous to the model are fixed at their 1982 levels. Income and population are projected to grow at annual rates of 1.0 and 0.8 percent per year, respectively. Exports for corn and beans are permitted to grow at a one percent rate per year. Government loan rates and target prices are fixed at their 1982 level.

\section{Results}

Since the central objective of the study is to gain some perspective on the economic effects of a functioning precipitation modification technology, and to identify distribution and effects of successful rainfall enhancement, several scenarios were conducted at increasing levels of spatial aggregation. Specifically, precipitation in July and August is augmented $20 \%$ above their last 10 -year average value for one and five consecutive years over single districts (east central and southeast districts of Illinois separately); a group of southern districts in a state (west-southwest, eastsoutheast, southwest, and southeast of Illinois); an entire state (Illinois); and a group of states (Illinois, Indiana and lowa).

For each scenario, the change in revenues (price times quantity) to producers within target regions (i.e., areas with precipitation enhancement) as well as nontarget regions are calculated on a total and per acre basis. The gains to consumers are measured in terms of the savings in income which result from having increased production and lowered prices of meat. ${ }^{8}$

\footnotetext{
${ }^{8}$ Technically, the gains to consumers are measured in terms of the dollar area behind the demand curve and above the price line (Just et al.). When demand is insensitive to changes in price, this is equivalent to a reduction in total expenditures on meat products.
} 
TABLE 5. Market simulations of augmenting July and August precipitation $20 \%$ in two districts (SE and EC) of Illinois ${ }^{\mathrm{a}}$.

\begin{tabular}{|c|c|c|c|c|c|c|c|c|}
\hline & \multicolumn{4}{|c|}{ South east district (CRD 9) } & \multicolumn{4}{|c|}{ East central district (CRD 5) } \\
\hline & \multicolumn{2}{|c|}{ One year increase } & \multicolumn{2}{|c|}{ Five year increase } & \multicolumn{2}{|c|}{ One year increase } & \multicolumn{2}{|c|}{ Five year increase } \\
\hline & $\begin{array}{l}\text { Total } \\
(000)\end{array}$ & $\begin{array}{l}\text { Per } \\
\text { acre }\end{array}$ & $\begin{array}{l}\text { Total } \\
(000)\end{array}$ & $\begin{array}{l}\text { Per } \\
\text { acre }\end{array}$ & $\begin{array}{l}\text { Total } \\
(000)\end{array}$ & $\begin{array}{l}\text { Per } \\
\text { acre }\end{array}$ & $\begin{array}{l}\text { Total } \\
(000)\end{array}$ & $\begin{array}{l}\text { Per } \\
\text { acre }\end{array}$ \\
\hline Target area & & & & & & & & \\
\hline $\begin{array}{l}\text { Corn } \\
\text { Soybeans }\end{array}$ & $\begin{array}{l}1776.2 \\
6588.6\end{array}$ & $\begin{array}{l}2.98 \\
9.97\end{array}$ & $\begin{array}{r}6609.7 \\
29910.0\end{array}$ & $\begin{array}{l}11.70 \\
39.12\end{array}$ & $\begin{array}{r}2732.6 \\
10317.1\end{array}$ & $\begin{array}{l}1.61 \\
7.52\end{array}$ & $\begin{array}{r}9935.9 \\
32043.1\end{array}$ & $\begin{array}{r}5.88 \\
24.96\end{array}$ \\
\hline $\begin{array}{l}\text { Remainder of llinois } \\
\text { Corn } \\
\text { Soybeans }\end{array}$ & $\begin{array}{l}-1032.3 \\
-1203.7\end{array}$ & $\begin{array}{l}-0.09 \\
-0.17\end{array}$ & $\begin{array}{r}-9290.4 \\
-13903.8\end{array}$ & $\begin{array}{l}-0.84 \\
-1.52\end{array}$ & $\begin{array}{l}-1549.2 \\
-1724.5\end{array}$ & $\begin{array}{l}-0.15 \\
-0.71\end{array}$ & $\begin{array}{l}-10040.6 \\
-13134.5\end{array}$ & $\begin{array}{l}-1.02 \\
-1.59\end{array}$ \\
\hline $\begin{array}{l}\text { Remainder of U.S. } \\
\text { Corn } \\
\text { Soybeans }\end{array}$ & $\begin{array}{l}-4802.9 \\
-6856.1\end{array}$ & $\begin{array}{l}-0.06 \\
-0.12\end{array}$ & $\begin{array}{l}-34571.4 \\
-59045.8\end{array}$ & $\begin{array}{l}-0.48 \\
-0.81\end{array}$ & $\begin{array}{r}-8014.1 \\
-11731.4\end{array}$ & $\begin{array}{l}-0.13 \\
-0.23\end{array}$ & $\begin{array}{l}-11731.4 \\
-85465.4\end{array}$ & $\begin{array}{l}-0.93 \\
-1.35\end{array}$ \\
\hline Savings to consumers & 2042.8 & & 15267.5 & & 3368.5 & & 24574.5 & \\
\hline
\end{tabular}

a Values are in dollars. For producers of corn and soybeans, they represent the change in revenues (total and on a per acre basis) from a one-year and a five-year increase in precipitation over a ten-year simulation period. The savings to consumers represent the gains in consumer surplus from a reduction in meat prices (see text for more discussion).

The average value of production per acre for Illinois and the remainder of the U.S. during 1978-82 were: Illinois: corn--\$305.16/acre, soybeans-\$233.58/acre; Remainder of the U.S.: corn-\$264.90/acre, soybeans-\$185.11/acre.

Tables 5 through 8 show the results of the simulations for various levels of spatial and temporal aggregations. ${ }^{9}$ Several important points emerge from examination of the results of the analysis. While small in most instances, the change in producer revenues for small units of spatial aggregation (Table 5, CRDs 9 and 5) are always positive. As the use of precipitation modification technology expands to larger land units, two patterns emerge. First, the change in total revenues to target areas increases initially and then begins to decline. For the levels of aggregation considered here, the change in revenues in portions of the target areas (e.g. Table 7, CRD NE) are negative. At multiple state levels, the change in total revenues to the target areas is negative (Table 8). Second, as a particular spatial unit (e.g., the CRD) is included in precipitation modification programs covering larger areas, its revenue from the program declines. These results follow from the size of the production increase and its effect on price.

At the smaller sizes of aggregations, producers in the target region have more output to sell, albeit at a slightly lower price. The reduction in prices results from an increase in production and the characteristics of demand for agricultural commodities that tend to be inelastic. In small areas, however, the percent increase in production outweighs the percent decrease in price;

\footnotetext{
${ }^{9}$ All calculations are discounted by 10 percent to obtain their present value. Caution should be taken in examining the revenue figures for producers and the savings to consumers; they are not directly comparable. The revenue figures do not include the costs of weather modification (see footnote 6 ). Also comparisons may not be strictly appropriate where the marginal value of income differs across the two groups.
}

thus the change in the total revenue to producers is positive. This situation changes as the size of the affected area increases. With an increasing area, the percent decrease in price tends to exceed the percent increase in production, resulting in a decline in total revenue even to producers in the target region. The magnitude of the reduction in total revenue can become large as the area of the programs is extended. For an individual area included in precipitation modification programs covering larger land units, the same increase in production from the modification efforts is sold at lower prices resulting in reduced revenues.

Producers in the nontarget areas are always faced with a reduction in total revenues. Clearly, this is due to the decline in prices with no increase in output in the nontarget areas. The reduction in total revenues in the nontarget areas exceeds the gains in the target areas due to their large production. As the size of target area increases, the magnitude of the reduction in total revenue in the nontarget area increases dramatically. That is, as the rainfall change occurs over ever larger Corn Belt areas, producing substantial increases in output, prices tend to decline rapidly.

In all scenarios examined, consumers gain because of the lower prices. This results from a lowering of prices of meat products and increased consurnption. As with the other measures, the size of consumer gains increases as the larger areas are simulated.

The results of the simulation also demonstrate the differential impacts of weather modification at similar levels of spatial aggregations. Based on per acre figures, it is clear that some regions are more responsive than others to a given level of precipitation enhancement, reflecting the differences in size, soil types, climatic conditions and acreage response across the regions. For 
TABLE 6. Market simulation of augmenting July and August precipitation $20 \%$ in west-southwest (WSW), east-southeast (ESE), southwest (SW), and southeast (SE) districts of Illinois ${ }^{\mathrm{a}}$.

\begin{tabular}{|c|c|c|c|c|}
\hline & \multicolumn{2}{|c|}{ One year increase } & \multicolumn{2}{|c|}{ Five year increase } \\
\hline & Total $(000)$ & Per acre & Total $(000)$ & Per acre \\
\hline \multicolumn{5}{|l|}{ Target area } \\
\hline \multicolumn{5}{|l|}{ Corn } \\
\hline WSW & 4743.1 & 3.46 & 16860.6 & 12.80 \\
\hline ESE & 3221.6 & 2.64 & 13087.4 & 9.66 \\
\hline SW & 2279.7 & 4.75 & 8286.9 & 18.79 \\
\hline $\mathrm{SE}$ & 1357.1 & 2.24 & 4735.0 & 8.30 \\
\hline Total & 12101.6 & & 42970.0 & \\
\hline \multicolumn{5}{|l|}{ Soybeans } \\
\hline WSW & 3496.0 & 2.75 & 10125.5 & 7.23 \\
\hline ESE & 13128.0 & 8.81 & 45824.3 & 28.19 \\
\hline SW & 5156.4 & 7.13 & 17686.1 & 22.80 \\
\hline $\mathrm{SE}$ & 6158.1 & 9.25 & 22646.5 & 23.79 \\
\hline Total & 27938.7 & . & 36282.6 & \\
\hline \multicolumn{5}{|l|}{ Remainder of Illinois } \\
\hline Corn & -2840.4 & -0.98 & -39416.9 & -4.97 \\
\hline Soybeans & -5365.2 & -1.23 & -32582.1 & -6.27 \\
\hline \multicolumn{5}{|l|}{ Remainder of U.S. } \\
\hline Corn & $-51 \quad 198.7$ & -0.83 & -261297.1 & -4.29 \\
\hline Soybeans & -53158.2 & -0.97 & -320443.1 & -4.99 \\
\hline Savings to consumers & 21540.9 & & 110946.3 & \\
\hline
\end{tabular}

${ }^{a}$ See Table 5 for a description of the components of the table.

TABLE 7. Market simulation of augmenting July and August precipitation $20 \%$ in Illinois ${ }^{\mathrm{a}}$.

\begin{tabular}{|c|c|c|c|c|}
\hline & \multicolumn{2}{|c|}{ One year increase } & \multicolumn{2}{|c|}{ Five year increase } \\
\hline & Total $(000)$ & Per acre & Total $(000)$ & Per acre \\
\hline \multicolumn{5}{|l|}{ Target area } \\
\hline \multicolumn{5}{|l|}{ Corn } \\
\hline NW & 4553.0 & 2.02 & 12623.5 & 5.80 \\
\hline $\mathrm{NE}$ & -666.4 & -0.54 & -6507.4 & -5.09 \\
\hline WC & -1971.2 & -1.81 & -9098.6 & -8.49 \\
\hline $\mathrm{C}$ & 2679.9 & 1.46 & 6715.5 & 3.74 \\
\hline EC & -1290.8 & -0.77 & -9710.8 & -5.75 \\
\hline WSW & 2641.8 & 1.86 & 7273.4 & 5.40 \\
\hline ESE & 1622.8 & 1.09 & 3593.5 & 2.54 \\
\hline SW & 1710.4 & 3.46 & 6027.5 & 13.47 \\
\hline SE & 594.2 & 0.90 & 1375.5 & 2.22 \\
\hline Total & 9873.8 & & 12292.3 & \\
\hline \multicolumn{5}{|l|}{ Soybeans } \\
\hline NW & 3436.9 & 5.70 & 9807.3 & 15.03 \\
\hline $\mathrm{NE}$ & 6830.7 & 8.24 & 21573.4 & 23.82 \\
\hline WC & -944.0 & -1.29 & -8364.5 & -9.49 \\
\hline $\mathrm{C}$ & 7464.7 & 6.59 & 21942.2 & 17.69 \\
\hline $\mathrm{EC}$ & 6728.7 & 4.86 & 18015.6 & 12.27 \\
\hline WSW & 1257.0 & 0.97 & -2302.1 & -1.29 \\
\hline ESE & 10779.3 & 7.22 & 33290.0 & 20.58 \\
\hline SW & 4097.1 & 5.71 & 12124.7 & 15.76 \\
\hline $\mathrm{SE}$ & 5375.4 & 8.01 & 17839.0 & 23.55 \\
\hline Total & 45026.0 & & 123925.9 & \\
\hline \multicolumn{5}{|l|}{ Remainder of U.S. } \\
\hline Corn & -136881.6 & -2.22 & -663409.7 & -10.90 \\
\hline Soybeans & -132215.4 & -1.97 & -751871.4 & -11.97 \\
\hline Savings to consumers & 57801.6 & & 280552.9 & \\
\hline
\end{tabular}

a See Table 5 for a description of the components of the table. 
TABLE 8. Market simulation of augmenting July and August precipitation $20 \%$ in Illinois, Indiana, and Iowa simultaneously .

\begin{tabular}{|c|c|c|c|c|}
\hline & \multicolumn{2}{|c|}{ One year increase } & \multicolumn{2}{|c|}{ Five year increase } \\
\hline & Total $(000)$ & Per acre & Total $(000)$ & Per acre \\
\hline \multicolumn{5}{|l|}{ Target area } \\
\hline $\begin{array}{l}\text { Illinois } \\
\text { Indiana } \\
\text { Iowa }\end{array}$ & $\begin{array}{l}-72302.6 \\
-28024.6 \\
-50005.0\end{array}$ & $\begin{array}{l}-6.25 \\
-4.52 \\
-3.77\end{array}$ & $\begin{array}{l}-322235.0 \\
-128699.0 \\
-250898.2\end{array}$ & $\begin{array}{l}-28.05 \\
-20.59 \\
-18.80\end{array}$ \\
\hline Total & -150332.3 & 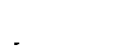 & -701832.2 & \\
\hline $\begin{array}{l}\text { Soybeans } \\
\text { Illinois } \\
\text { Indiana } \\
\text { Iowa }\end{array}$ & $\begin{array}{r}-7817.6 \\
-4786.0 \\
-30888.8\end{array}$ & $\begin{array}{l}-0.54 \\
-0.70 \\
-3.61\end{array}$ & $\begin{array}{r}-116976.5 \\
-61510.1 \\
-196704.3\end{array}$ & $\begin{array}{l}-10.96 \\
-11.71 \\
-21.79\end{array}$ \\
\hline Total & -43492.5 & & -375190.9 & \\
\hline $\begin{array}{l}\text { Remainder of U.S. } \\
\quad \text { Corn } \\
\text { Soybeans }\end{array}$ & $\begin{array}{l}-320288.7 \\
-305587.7\end{array}$ & $\begin{array}{l}-7.66 \\
-6.49\end{array}$ & $\begin{array}{l}-1383662.8 \\
-1508609.6\end{array}$ & $\begin{array}{l}-33.58 \\
-29.22\end{array}$ \\
\hline Savings to consumers & 189046.4 & & 804787.1 & \\
\hline
\end{tabular}

${ }^{a}$ See Table 5 for a description of the components of the table.

example, a comparison of the per acre figures in Table 5 shows the differential impact of the same level of increase in rainfall when applied over single crop districts in Illinois. A more direct comparison can be made using Table 6 and Table 7 . Since the districts face the same prices, any differences in the per acre change in revenue are primarily the result of the differences in the agronomic response to the change in rainfall. Identifying such differences in the responsiveness of the regions to given levels of technology is useful in evaluating the allocation of the resources across the regions and understanding differences in producer motivation for participating in precipitation modification programs.

The results also provide some insight into the effects of a continued precipitation modification program (five years). Continued successful programs of precipitation modification increase substantially the magnitude of the effects on producer revenues in target and nontarget areas and result in consumer savings. However, this increase is not uniform nor of a constant percentage across the regions examined. For example, consider Table 6 where the changes in revenue on a total and per acre basis for corn and soybeans increase by differing percentages in the regions over the ten-year period. These differences reflect the varying responsiveness of the agro-economic environment in each region. These changes in revenues associated with the more prolonged modification programs should be examined cautiously as successful weather modification over time may change production and technological responses within and outside the target areas. This in turn will likely influence the calculated effects.

The results of the simulation shed light on producer motivation to participate in precipitation modification programs. For a small area (e.g., CRD), participation in a precipitation modification program can be bene- ficial as the small increase in production will not cause prices to decline by a significant amount. From the viewpoint of this region, the magnitude of the increase in revenues is largest when the modification technology is least extensively employed. From another perspective, the value of the modification technology to a region increases when its own use of the technology precedes wide spread technological dissemination. Also, even when the change in the revenue in the target areas is negative, the losses for an individual area are likely to be smaller with precipitation modification than without. A comparison of the changes in revenues on a per acre basis for all simulations finds that on average it is more attractive for a region to be in the target area than outside. This occurs because the increased precipitation on a small unit means additional output with only a small additional decline in price. Clearly, for an individual region considering the use of precipitation modification technology, this is preferable to the case where price declines and there is no added output. These findings suggest that there is strong incentive for the producers in particular regions to adopt and support the successful weather modification technologies.

\section{Summary and conclusions}

Several important findings emerge concerning the effects of a functioning precipitation modification technology. Regional and temporal considerations are important in determining the effects of precipitation modification on revenues of producers. Differences in soil types, climatic conditions and acreage response influence the magnitude of the revenues for a given level of precipitation enhancement. Similarly, the size of the target area affects producer revenues from use of the technology. Given other factors, when the target region is small, the producers within that region experience 
the largest gains in revenues. Similarly, with a small target area, producers outside the region experience only small reductions in revenue. As a particular spatial region is included in precipitation modification programs covering larger areas, its revenue resulting from the program declines. For programs covering multistate areas, the change in total revenues to the target areas is negative. The reduction in revenues of producers in nontarget regions increases substantially as the size of the target region increases. Temporally, revenues to the target areas increase from added precipitation over time. The results also indicate that there is a strong incentive for producers to adopt the technology in the early stages of the precipitation modification programs and for producers outside the target regions to use the precipitation technology.

This study provides insight into the nature of precipitation modification programs and issues of funding by producers and consumers of operational precipitation modification projects and funding of R \& D on precipitation modification. First, from the perspective of the producers in a target area, the increase in revenue from added precipitation over time favors multiyear use of the precipitation modification technology. This is in contrast to one-year isolated usage of precipitation modification technology which has been typical of past modification efforts. In turn, this suggests the need to consider the development of institutions to manage such programs.

Second, the sentiment among producers, given the highly variable nature of revenue from precipitation modification across areas, seems to be that the most direct beneficiaries of the technology should support its operation and maintenance. Such a policy would eliminate some of the difficulties of large-area precipitation modification programs that would charge producers equally but would result in highly divergent increases in revenues across regions. The results that indicate positive increases in revenues accruing to producers up the state scale suggest that operational projects might be more easily organized and funded to attract producer participation, mostly at local and state levels.

Third, the nature of the changes in producer revenues and the findings that consumers benefit from modification technologies and the potential use of precipitation modification technologies across regions support the concept that funding responsibilities for $\mathrm{R}$ \& D should fall on more aggregate government units, i.e., state and federal. The small size of the changes in producer revenue in certain areas and their variability across regions may make it difficult to generate support for local funding of $\mathrm{R} \& \mathrm{D}$ for weather modification. In addition, the magnitude of the investment in precipitation modification may be too large for state governments alone (Changnon et al. 1978). The findings that consumers always benefit from modification technology suggest that they should bear part of the cost of its complete development. Given that the spatial distribution of consumers may not coincide with regions where weather modification is employed, it may be more effective for more aggregate government units to redistribute the gains from the technology. In addition, since the technology could be used in various parts of the nation, a federally coordinated effort across regions and states may be the most effective structure to facilitate the funding and development of precipitation modification technologies.

Finally, it is clear that large-scale precipitation modification reduces the revenues to producers making its use less attractive. This suggests that the development of precipitation modification technologies should be coordinated with market expansion and demand creation strategies so that the profitability of these new technologies may be maintained. Without such an effort, the attractiveness of these supply-increasing technologies may be reduced.

Acknowledgments. The research was supported in part by two grants from NOAA, NA85RAHJ05060 and NA88RAH0810.

APPENDIX

\section{Structure of the Model}

This appendix provides a more comprehensive discussion of the model. The basic structure of the livestock and corn sector is presented in Offutt and Blandford (1984). More detailed information on the other equations, the variables and the sources of the data are presented in Garcia et al. (1985, 1986). The presentation here, briefly touches on selected econometric considerations and concentrates on the interrelationships between the livestock and corn and soybean sectors. Recall that weather enters into the model through its effects on corn and soybean yields (discussed in the text) which modify production and prices. Fluctuating feed prices influence subsequent livestock production, which in turn affects meat product prices.

The econometric model is annual in period, except for the hog production sector, which is semiannual to reflect the production characteristics of this sector, and is estimated over the period 1961-82. All behavioral equations are estimated by ordinary or generalized least squares since, although some simultaneity exists, the bulk of the model is recursive. The model is validated and simulated in its structural form, using the iterative Newton solution procedure.

\section{The livestock component}

The livestock sector is divided into hogs, fed and nonfed cattle, and poultry to allow an accurate portrayal of differential responses that arise due to differences in the biological, technical, and economic aspects of production processes. 
In general, the equations that describe the hog and beef cattle production processes are recursive-i.e., influenced by lagged prices-and reflect the biological processes that constrain supply at any given point in time and contribute to the existence of multiyear cycles. As pointed out by Nerlove (1979), and Chavas and Johnson (1982), this formulation allows a better picture of the influence of changes in feed prices on livestock production. Thus, the inclusion of biological lags permits these effects to be traced through the production processes to their final manifestation in livestock product supply.

In the hog and beef cattle sector, animal numbers in the short run are largely fixed. Given animal numbers, the short-run response to changes in corn price depends on ration flexibility (availability of substitutes for corn ) and on production flexibility (ability to modify output with no change in animal numbers). Longerrun response depends on the way in which expected prices affect inventory adjustment decisions.

In the beef sector, the corn price affects production in the short run through the slaughter mix of fed versus nonfed beef and the average finished weight of fed cattle. Slaughter of nonfed beef depends on the feeder cattle price, which is itself a positive function of the expected fed beef/corn price ratio. An increase in corn price (which decreases feeder cattle profitability) increases nonfed beef supply as cattle bypass feedlots and are finished on forage. In the longer run, corn price affects breeding inventories through its effect on the number of cows slaughtered (another source of nonfed beef in the short run) and heifers added.

In the hog sector, the model reflects the facts that there are few substitutes for corn, and a fed or nonfed marketing option is not available. Moreover, once a hog attains a weight of about 240 pounds, it must be sent to slaughter. Thus, hog producers are, within a 6month period, price takers. Price is dependent on current supply, which is determined by the previous period's pig crop, and is a function of inventory decisions made at least one year earlier. The slaughter of breeding sows represents the only source of short-run adjustment in the sector.

Another factor which influences corn demand and also influences soybean meal demand is the level of broiler production. Since World War II, growth in per capita consumption of broilers has doubled and redoubled. Per capita consumption in 1980 was 50 pounds, compared with 28 pounds in 1960. This rapid expansion in the broiler industry has occurred with significant changes in its industrial structure and technological procedures. Such structural and technical change, coupled with a relatively short production cycle, complicate attempts to model broiler output over the past 20 years in an annual framework. Consequently, broiler production is modeled rather simply with output a function of broiler price, the price of corn, the price of soybean meal, and a linear time trend included to capture the effects of structural and technical change.

The interaction between the demand for livestock products and their supply determines overall production and price levels. The consumer demand for livestock is modeled under the maintained hypothesis that, within a specified period, the supply of livestock products is largely fixed, so prices, not quantities, adjust to clear the market. This specification is justifiable as being an accurate representation of livestock product markets and is also consistent with maximizing consumer behavior.

In the demand equations, price depends on the quantities of the livestock product available for consumption, whose price is being considered as well as on the quantities of its potential substitutes and complements. Disposable income is also included as an explanatory variable. All quantity variables and disposable income are in per capita terms. Prices and income appear in nominal, not deflated, form since the hypothesis that consumers suffered no money illusion was rejected.

\section{The corn and soybean components}

The level of production for each crop interacts with the various demand components to determine price and allocation. The total production of corn and soybeans in any period is a summation of the product of yield and acreage for each region in the model. The domestic demand is comprised of a demand for seed, industrial use, food, exports, and feed use.

The demand for corn and soybeans is heavily influenced by livestock numbers. Hog and cattle production in the United States account for two thirds of all corn fed. The remainder is split evenly between poultry and dairy industries. Poultry production accounts for the large part of soybean meal consumed domestically.

In the model, the aggregate feed demand for corn arises from the derived demand in the various livestock sectors, in which feed needs are closely related to livestock production levels. The total demand for corn is equal to the level of production multiplied by a corn conversion or requirement rate per unit of output.

For beef cattle, derived corn demand is a stochastic function of fed beef production in pounds of finished liveweight. In contrast, the derived demand for corn by the hog sector is described as a nonstochastic function of the number of head of hogs slaughtered multiplied by the average annual amount of corn fed per hog, which remained relatively constant throughout the period.

The derived demand for corn by broilers and other poultry is specified as a function of broilers and the corn/broiler price ratio. The dependent variable includes not only broiler corn use but that of hens and pullets, chickens raised for replacement, and turkeys. The absolute amount of corn consumed by these other 
poultry types has changed very little over the past 20 years. The growth in corn use has come from the broiler sector, where total use almost doubled from 1960 to 1980.

The soybean complex involves a complicated set of relationships that link the demand for soyoil, soybean meal, and soybeans. With regard to the corn and livestock sector of the model, the important relationships can be adequately modeled by focusing on the derived demand soybean meal, soybeans, and the linkages to poultry production. The soybean meal price affects the profitability of broiler production; i.e., lower soybean meal prices result in higher profits in broiler production and increased output. Similarly, increased broiler production is associated with greater demand for the high concentrate protein that soybean meal provides as well as higher soybean meal prices.

Specifically, the quantity of soybean meal consumed is influenced by the soybean meal price, corn price, broiler production, and the use of other high protein feeds. The demand for soybean meal and the price of soybeans, the price of soyoil, the wholesale soybean price, and crushing capacity determine the quantity of soybeans crushed. Soybean commercial stocks are affected by market price, production of soybeans, lagged private stocks and government stocks. The quantity demanded for commercial stocks, in conjunction with the quantity crushed, the demand for exported beans, and beginning stocks, affect the wholesale market price of soybeans. The soybean wholesale market price then influences the soybean price at the producer level. The system is closed with stock identities for soybean meal and soybeans. Here, the soybean oil sector and the export components of soybeans and soybean meal are exogenous (Good et al. 1980). Also, note that current production of soybeans enters into the commercial stock relationship, which affects soybean wholesale and farm level prices.

\section{REFERENCES}

Changnon, S. A., 1980a: Weather modification: Impacts and implications. State Government, 2-6. 1980b: The rationale for future weather modification research. Bull. Amer. Meteor. Soc., 61, 546-551.

- $1980 \mathrm{c}$ : Weather modification: Winners and losers. Water Spectrum, 12, 28-40.

__ 1983: Governmental roles in planned weather modification. Proceedings of Conference on Advances in Irrigation and Drainage: Surviving External Pressures, Amer. Soc. Civil Engineers, 8 pp.

- 1986: Illinois weather modification program, PACE. Preprints 10th Conference on Weather Modification: A Review. Boston, Amer. Meteor. Soc., 315-319.

- - and W. H. Lambright, 1987: The rise and fall of federal weather modification policy. J. Wea. Mod., 19, 1-12.

-, B. Farhar and E. Swanson, 1978: Hail suppression and society. Science, 200, 387-394.

-, R. G. Semonin, A. Auer, R. R. Braham and J. Hales, 1981: MEMOTREX: A Review and Summary. Meteor. Monograph., No. 18, Amer. Meteor. Soc., 81 pp.

Chavas, J., and S. R. Johnson, 1982: Supply dynamics: The case of U.S. broilers and turkeys. Amer. J. Agric. Econ., 64, 558-888.

Garcia, P., S. E. Offutt and M. Pinar, 1985: Agricultural economic modeling. Annual Report for Crops Experiment. Illinois State Water Survey, SWS Contract Report 365, pp. 1-37.

- - - - and - 1986: Agricultural economic modeling studies. Final report of the precipitation augmentation for crops experiment: Pre-experimental phase studies, Illinois State Water Survey, Contract Report 404, pp. 2.1-2.117.

$-, \ldots, \ldots$ and S. Changnon, 1987: Crop yield behavior: Effects of technological advance and weather conditions. J. Climate Appl. Meteor., 26, 1092-1102.

Good, D. L., T. A. Hieronymus and R. A. Hinton, 1980: Price Forecasting and Sales Management. College of Agriculture, Illinois Cooperative Extension.

Houck, J. P., and M. E. Ryan, 1972: Supply analysis for corn in the United States: The Impact of changing government programs. Amer. J. Agric. Econ., 54, 184-91.

Just, R. E., D. L. Hueth and A. Schmitz, 1982: Applied Welfare Economics and Public Policy. Prentice-Hall.

Nerlove, M., 1979: The dynamics of supply: Retrospect and prospect. Amer. J. Agric. Econ., 61, 874-888.

Offutt, S. E., 1988: Aggregating crop production data: A random coefficient approach. Agric. Econ. Res. 40, 11-18.

_- and D. Blandford, 1984: The impact of the Soviet Union upon the U.S. feed/livestock sector-An assessment. J. Policy Modeling, 6, 311-340.

Sonka, S. T., 1979: Economics of weather modification: A review. Report of Investigation 89, Illinois State Water Survey, Urbana, $57 \mathrm{pp}$.

Weather Modification Advisory Board, 1978: The Management of Weather Resources. U.S. Department of Commerce, Washington, DC., $210 \mathrm{pp}$. 